\title{
Anti-tax interacting protein-1 (TIP-1) monoclonal antibody targets human cancers
}

\author{
Heping Yan ${ }^{1, *}$, Vaishali Kapoor ${ }^{1, *}$, Kim Nguyen ${ }^{1}$, Walter J. Akers ${ }^{2,3}$, Hua Li ${ }^{1}$, Jalen \\ Scott $^{1}$, Richard Laforest ${ }^{2}$, Buck Rogers ${ }^{1}$, Dinesh Thotala ${ }^{1,3}$ Dennis Hallahan ${ }^{1,2,3}$ \\ ${ }^{1}$ Department of Radiation Oncology, Washington University in St. Louis, St. Louis, Missouri, USA \\ ${ }^{2}$ Mallinckrodt Institute of Radiology, Washington University in St. Louis, St. Louis, Missouri, USA \\ ${ }^{3}$ Siteman Cancer Center, School of Medicine, Washington University in St. Louis, St. Louis, Missouri, USA \\ *Co-first authors
}

Correspondence to: Dennis Hallahan, email: dhallahan@radonc.wustl.edu

Keywords: TIP-1, radiation-inducible, monoclonal antibody, radioimmunotherapy, in vivo imaging

Received: March 11, $2016 \quad$ Accepted: May 13, $2016 \quad$ Published: May 30, 2016

\section{ABSTRACT}

Radiation-inducible neo-antigens are proteins expressed on cancer cell surface after exposure to ionizing radiation (IR). These neo-antigens provide opportunities to specifically target cancers while sparing normal tissues. Tax interacting protein-1 (TIP-1) is induced by irradiation and is translocated to the surface of cancer cells. We have developed a monoclonal antibody, 2C6F3, against TIP-1.

Epitope mapping revealed that $2 \mathrm{C} 6 \mathrm{~F} 3$ binds to the QPVTAVVQRV epitope of the TIP-1 protein. 2C6F3 binds to the surface of lung cancer (A549, LLC) and glioma (D54, GL261) cell lines. 2C6F3 binds specifically to TIP-1 and ELISA analysis showed that unconjugated 2C6F3 efficiently blocked binding of radiolabeled $2 \mathrm{C} 6 \mathrm{~F} 3$ to purified TIP-1 protein. To study in vivo tumor binding, we injected near infrared (NIR) fluorochrome-conjugated 2C6F3 via tail vein in mice bearing subcutaneous LLC and GL261 heterotopic tumors. The NIR images indicated that 2C6F3 bound specifically to irradiated LLC and GL261 tumors, with little or no binding in un-irradiated tumors.

We also determined the specificity of $2 \mathrm{C} 6 \mathrm{~F} 3$ to bind tumors in vivo using SPECT/ CT imaging. 2C6F3 was conjugated with diethylene triamine penta acetic acid (DTPA) chelator and radiolabeled with ${ }^{111}$ Indium ( $\left.{ }^{111} \mathrm{In}\right)$. SPECT/CT imaging revealed that ${ }^{111}$ In-2C6F3 bound more to the irradiated LLC tumors compared to un-irradiated tumors. Furthermore, injection of DTPA-2C6F3 labeled with the therapeutic radioisotope, ${ }^{90} \mathrm{Y}$, ( $\left.{ }^{90} \mathrm{Y}-\mathrm{DTPA}-2 \mathrm{C} 6 \mathrm{~F} 3\right)$ significantly delayed LLC tumor growth. 2C6F3 mediated antibody dependent cell-mediated cytotoxicity (ADCC) and antibody dependent cell-mediated phagocytosis (ADCP) in vitro.

In conclusion, the monoclonal antibody $2 \mathrm{C} 6 \mathrm{~F} 3$ binds specifically to TIP-1 on cancer and radio-immunoconjugated 2C6F3 improves tumor control.

\section{INTRODUCTION}

Tumor-specific targeted drug delivery has the potential to improve the efficacy of cytotoxic agents against tumors while minimizing toxicity to normal tissues. Monoclonal antibodies (mAbs) are one class of agents that can be used for cancer-specific therapeutic and diagnostic applications. mAbs achieve therapeutic effects by (i) antagonizing the receptor signaling or turnover directly (ii) affecting the vasculature or stroma indirectly or (iii) invoking an immune response through activation of complement-dependent cytotoxicity or antibody-dependent cellular toxicity $[1,2]$. mAbs have also been conjugated to cytotoxic drugs or radionuclides to directly target cancer cells [3]. Antibodies recognizing biomarkers expressed on the surface of the cancer cells or the tumor vasculature have been successfully used in the clinic. These include bevacizumab that targets VEGF, cetuximab that targets EGFR, pembrolizumab that targets PD1 (T cells), ipilimumab that targets CTLA4 (T cells) 
and trastuzumab that targets HER2 [4, 5]. Several new surface biomarkers for cancer are being identified and tested pre-clinically for their suitability to be used as targets for immunotherapy.

We previously identified a radiation-inducible neoantigen, Tax interacting protein 1 (TIP-1, also known as Tax 1 binding protein 3 , (Tax1BP3), that translocates to the cancer cell surface following irradiation [6]. TIP-1 was initially identified as one of the binding partners of the T-cell leukemia viral oncoprotein Tax $[6,7]$. A single PSD-95/DlgA/ZO-1 (PDZ) domain (89 amino acids) is the only structural and functional unit in the small protein (total of 124 amino acids in human and mouse), distinguishing TIP-1 from other PDZ proteins. TIP-1 functions as a scaffold for protein complex assembly and is highly conserved across species [8]. TIP-1 plays an important role in cancer, directly or indirectly regulating various signaling pathways that are involved in cancer development and progression. Overexpression of TIP-1 is implicated in cancer cell adhesion, migration, and metastasis [9]. Recently TIP-1 was shown to activate Rho GTPases and facilitate cell migration in glioblastoma [10]. Mouse models of lung cancer were specifically targeted by TIP-1 specific peptide HVGGSSV $[11,12]$. Overall, TIP-1's involvement in many different cancer pathways demonstrates its potential to be explored as a molecular target for cancer therapy.

In the present study, we developed a monoclonal antibody against TIP-1, 2C6F3. We show that it binds to the surface of cancer cells and specifically to radiationinducible TIP-1. 2C6F3 was conjugated to a radioisotope and was successfully used as a radio-immunoconjugate for the treatment of lung cancer models in mice.

\section{RESULTS}

\section{The specificity of the $2 \mathrm{C} 6 \mathrm{~F} 3$ antibody}

The specificity of the monoclonal antibody 2C6F3 to TIP-1 was determined by using immunoblotting. We titrated various concentrations of TIP-1 $(50,100,150$, 200 and $250 \mathrm{nM}$ ) with $25 \mathrm{nM}$ TIP-1 monoclonal antibody 2C6F3 (Supplementary Figure S1A). The TIP1 monoclonal antibody $2 \mathrm{C} 6 \mathrm{~F} 3$ detected all concentrations of TIP-1 protein. There was no significant difference in detection of the lowest concentration (50 ng) to the highest concentration (250 ng). We also evaluated the cytosolic induction of TIP-1 protein after irradiation. We irradiated A549, D54 and LLC cells with 3 Gy and immunoblotted for TIP-1 at 24 and 48 h (Supplementary Figure S1B). We found induction of TIP-1 at $24 \mathrm{~h}$ and 48 $\mathrm{h}$ in irradiated A549, D54 and LLC cells when compared to sham alone. There was a slight increase in TIP-1 induction in all the 3 cell lines at $48 \mathrm{~h}$ compared to $24 \mathrm{~h}$.

\section{Epitope mapping of 2C6F3 and modeling of 2C6F3 epitope on the TIP-1 protein}

We developed a monoclonal antibody against mammalian TIP-1, 2C6F3. The mammalian TIP-1 comprised of a single PDZ domain consists of 124 amino acids. We mapped the epitope of the 2C6F3 monoclonal antibody in the TIP-1 protein as described above. Epitope mapping indicated that $2 \mathrm{C} 6 \mathrm{~F} 3$ specifically bound to amino acids QPVTAVVQRV (Figure 1A; yellow highlighted region). These amino acids are located in the $\mathrm{N}$-terminal region of TIP-1 and just next to the beginning of the

$\begin{array}{rrrrrr}\text { A } & 10 & 20 & 30 & 40 & 50 \\ \text { MSYIPGQPVT } & \text { AVVQRVEIHK } & \text { LRQGENLILG } & \text { FSIGGGIDQD } & \text { PSQNPFSEDK } \\ 60 & 70 & 80 & 90 & 100 \\ \text { TDKGIYVTRV } & \text { SEGGPAEIAG } & \text { LQIGDKIMQV } & \text { NGWDMTMVTH } & \text { DQARKRLTKR } \\ 110 & 120 & & & \\ \text { SEEVVRLLVT } & \text { RQSLQKAVQQ } & \text { SMLS } & & \end{array}$

B

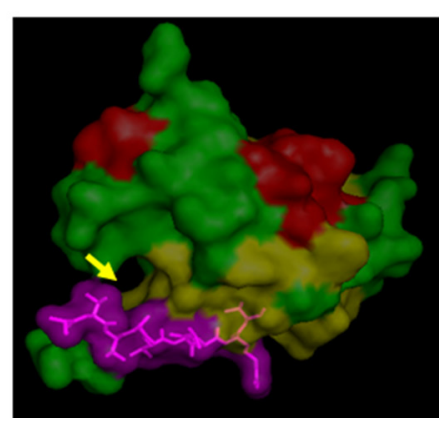

C

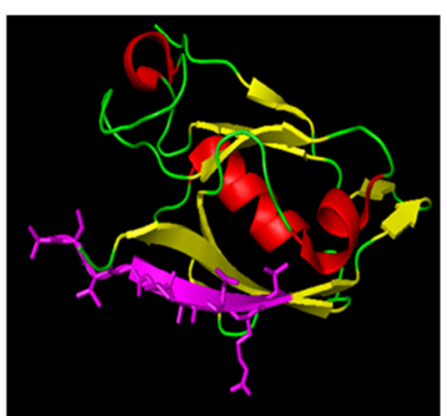

Figure 1: Epitope mapping of 2C6F3 and its location on the TIP-1 protein. (A) The sequence of the TIP-1 protein with red letters indicating the PDZ domain; the amino acids highlighted in yellow represent the epitope binding sequence of the $2 \mathrm{C} 6 \mathrm{~F} 3 \mathrm{monoclonal}$ antibody. (B) 3D structure of TIP-1 indicating the 2C6F3 epitope (violet) and the canonical peptide-binding pocket of the PDZ domain (yellow arrow). (C) Ribbon model of TIP-1 showing the location of the 2C6F3 Ab epitope (shown in violet). 
PDZ domain indicated in red letters. Previously the highresolution crystal structure of TIP-1 in complex with the C-terminal peptide of $\beta$-catenin has been elucidated [13]. The 3D modeling depicting the canonical peptide-binding pocket of the PDZ domain (yellow arrow) and the 2C6F3 epitope (violet region) are shown in Figure $1 \mathrm{~B}$ and $1 \mathrm{C}$.

Modeling of QPVTAVVQRV in the threedimensional crystal structure of TIP-1 using PyMOL software indicated that although $2 \mathrm{C} 6 \mathrm{~F} 3$ does bind in the N-terminal region of TIP-1, it does not bind in the canonical peptide-binding pocket (Figure 1B and 1C).

\section{C6F3 binds to cancer cell surface and Tip-1 protein in vitro}

Binding of 2C6F3 to the surface of cancer cells was evaluated by flow cytometry. A549 (lung cancer) and D54 (glioblastoma) cells were irradiated $(3 \mathrm{~Gy} \times 3)$ to induce the surface expression of TIP-1 and then incubated with $2 \mathrm{C} 6 \mathrm{~F} 3$ antibody followed by incubation with secondary antibody. A549 and D54 cells treated with the secondary antibody alone were used as negative controls. The flow cytometric analysis indicated that $2 \mathrm{C} 6 \mathrm{~F} 3$ bound to the cell surface of both A549 and D54 cells (Figure 2A). There was an 11 and 2 fold increase of cell surface associated TIP-1 at $24 \mathrm{~h}$ post-IR in A549 and D54 cells respectively. There was no significant increase in expression of surface TIP-1 in A549 at $48 \mathrm{~h}$ compared to $24 \mathrm{~h}$. There was a 1.8 fold increase in cell surface expression of TIP-1 in D54 at $48 \mathrm{~h}$ when compared to $24 \mathrm{~h}$ in the D54 cells (Figure 2B).

\section{C6F3 binds to mouse tumors in vivo}

We next evaluated the efficacy of binding of $2 \mathrm{C} 6 \mathrm{~F} 3$ to mouse tumor models by optical imaging. We performed near infrared imaging (NIR) of heterotopic tumors of Lewis lung cancer (LLC) and glioblastoma (GL261). Tumors on the right hind limb were irradiated with 3 fractions of 3 Gy over a course of $24 \mathrm{~h}$ while the tumor on the left hind limb was used as the shamirradiated control. The mice were then injected with $50 \mu \mathrm{g}$ of 2C6F3-Alexa flour 750 (2C6F3-AF750) or $50 \mu \mathrm{g}$ normal mouse IgG-Alexa flour 750 (IgG-AF750). The NIR imaging was performed at $24 \mathrm{~h}, 48 \mathrm{~h}, 72 \mathrm{~h}$ and $96 \mathrm{~h}$ post antibody injection (Figure 3A). Significant accumulation of the TIP-1 antibody (2C6F3) was observed in irradiated tumors when compared to normal $\mathrm{IgG}$ in both LLC and GL261tumors (Figure 3). Mice injected with 2C6F3-AF750 had 2099 a.u. in GL261 and 926 a.u. in LLC tumors at 24 hours following irradiation while unirradiated tumors had significantly less accumulation of 780 and 683 a.u. in GL261 and LLC tumors respectively (Figure 3B). At $48 \mathrm{~h}$ similar accumulation of 451 a.u. (GL261) and 466 a.u (LLC) was seen in irradiated tumors compared to 186 a.u. (GL261) and 271 a.u. (LLC) in unirradiated tumors. At 72 and $96 \mathrm{~h}$ there were no significant differences in 2C6F3-AF750 accumulation in irradiated compared to un-irradiated tumors. Low binding of normal mouse IgG-AF750 was observed in both GL261 and LLC tumors at all time points after irradiation or sham treatment (Figure 3B).

\section{${ }^{125}$ I-2C6F3 antibody retains TIP-1 specificity and binds specifically to tumors in vivo}

We next wanted to evaluate the efficacy of tumor binding of 2C6F3 antibody after conjugation of ${ }^{125} \mathrm{I}$ radioisotope. To confirm that ${ }^{125} \mathrm{I}$-labeled $2 \mathrm{C} 6 \mathrm{~F} 3$ retained its specificity to TIP-1 we did competition studies with cold $2 \mathrm{C} 6 \mathrm{~F} 3$. We found that ${ }^{125} \mathrm{I}$-labeled $2 \mathrm{C} 6 \mathrm{~F} 3$ retained
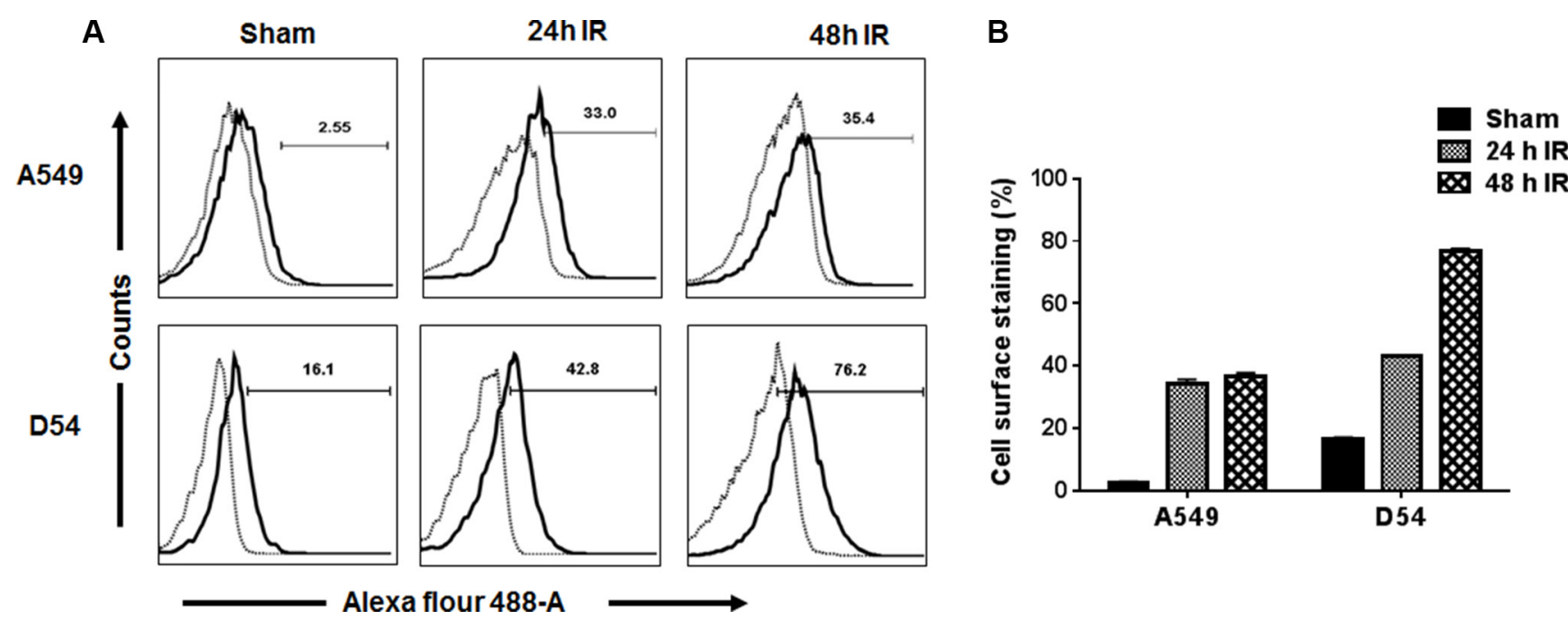

Figure 2: Flow cytometric analysis of the binding of 2C6F3 to the surface of human lung and glioblastoma cells. A549 and D54 cells were irradiated with 3 Gy or sham treated. At $24 \mathrm{~h}$ and $48 \mathrm{~h}$ post-irradiation, cells were collected and stained with 2C6F3 and a secondary antibody labeled with Alexa Flour 488. Shown are the overlay histograms (A) and bar graphs (B) of cell surface staining in each treatment with SD of three samples. 
its binding specificity at as low as $0.001 \mu \mathrm{g}$ to $1 \mu \mathrm{g}$ of recombinant TIP-1 protein (Figure 4A). The cold 2C6F3 (200 fold excess) was able to block the binding of ${ }^{125}$ I-labeled 2C6F3 to recombinant TIP-1.

We performed SPECT/CT imaging with ${ }^{125} \mathrm{I}$-labeled 2C6F3 on heterotopic LLC tumors in C57BL/6 mice. The tumors were irradiated with 3 fractions 3 Gy over a course of $24 \mathrm{~h}$. The mice were then injected with $120 \mu \mathrm{Ci}$ of ${ }^{125} \mathrm{I}$-labeled $2 \mathrm{C} 6 \mathrm{~F} 3$ via the tail vein. SPECT/CT imaging was performed at $48 \mathrm{~h}$ post injection. The SPECT images revealed that ${ }^{125} \mathrm{I}$-labeled $2 \mathrm{C} 6 \mathrm{~F} 3$ bound specifically to the irradiated LLC tumors (Figure 4B). Very low or negligible binding of ${ }^{125} \mathrm{I}$-labeled $2 \mathrm{C} 6 \mathrm{~F} 3$ was observed in shamirradiated tumors (Figure 4B).

\section{${ }^{111}$ In-2C6F3 labeled antibody binds specifically to tumors in vivo}

Indium DTPA ( $\left.{ }^{111} \mathrm{In}-\mathrm{DTPA}\right)$ is a diagnostic agent and used routinely for cancer imaging. We first conjugated 2C6F3 with DTPA and evaluated the specificity of the DTPA-2C6F3 to TIP-1. We determined that DTPA-2C6F3 retained its specificity for TIP-1 similar to that of $2 \mathrm{C} 6 \mathrm{~F} 3$ alone (data not shown). We then labeled DTPA-2C6F3 with ${ }^{111}$ In and performed SPECT/ CT imaging using heterotopic LLC tumors. Tumors were irradiated with 3 fractions of 3 Gy over the course of 24 hours or sham irradiated. The mice were then injected with $250 \mu \mathrm{Ci}$ of radiolabeled DTPA-2C6F3 via the tail vein. SPECT/CT imaging was performed at 48 and $72 \mathrm{~h}$ post injection. The SPECT imaging at $48 \mathrm{~h}$ and $72 \mathrm{~h}$ post injection revealed that ${ }^{111}$ In-labeled DTPA$2 \mathrm{C} 6 \mathrm{~F} 3$ bound to both sham and irradiated LLC tumors (Figure 5A). More ${ }^{111}$ In-DTPA-2C6F3 was bound in the irradiated tumors at $48 \mathrm{~h}$ and $72 \mathrm{~h}$ compared to shamirradiated control tumors, although not at significant levels (Figure 5B).

The biodistribution of ${ }^{111}$ In-DTPA-2C6F3 was determined at $48 \mathrm{~h}$ and $72 \mathrm{~h}$ post injection. ${ }^{111} \mathrm{In}$ labeled DTPA-2C6F3 accumulated in the blood, liver and tumors in the in tumor-bearing mice (Figure $5 \mathrm{C}$ ). The radiolabeled $2 \mathrm{C} 6 \mathrm{~F} 3$ was still in circulation as observed by the blood uptake in the biodistribution data. Labeled 2C6F3 was also observed in the liver as these antibodies were being cleared from the circulation. The levels of the labeled antibody in lung, spleen, kidney, adrenals, pancreas, stomach, and intestine were low.
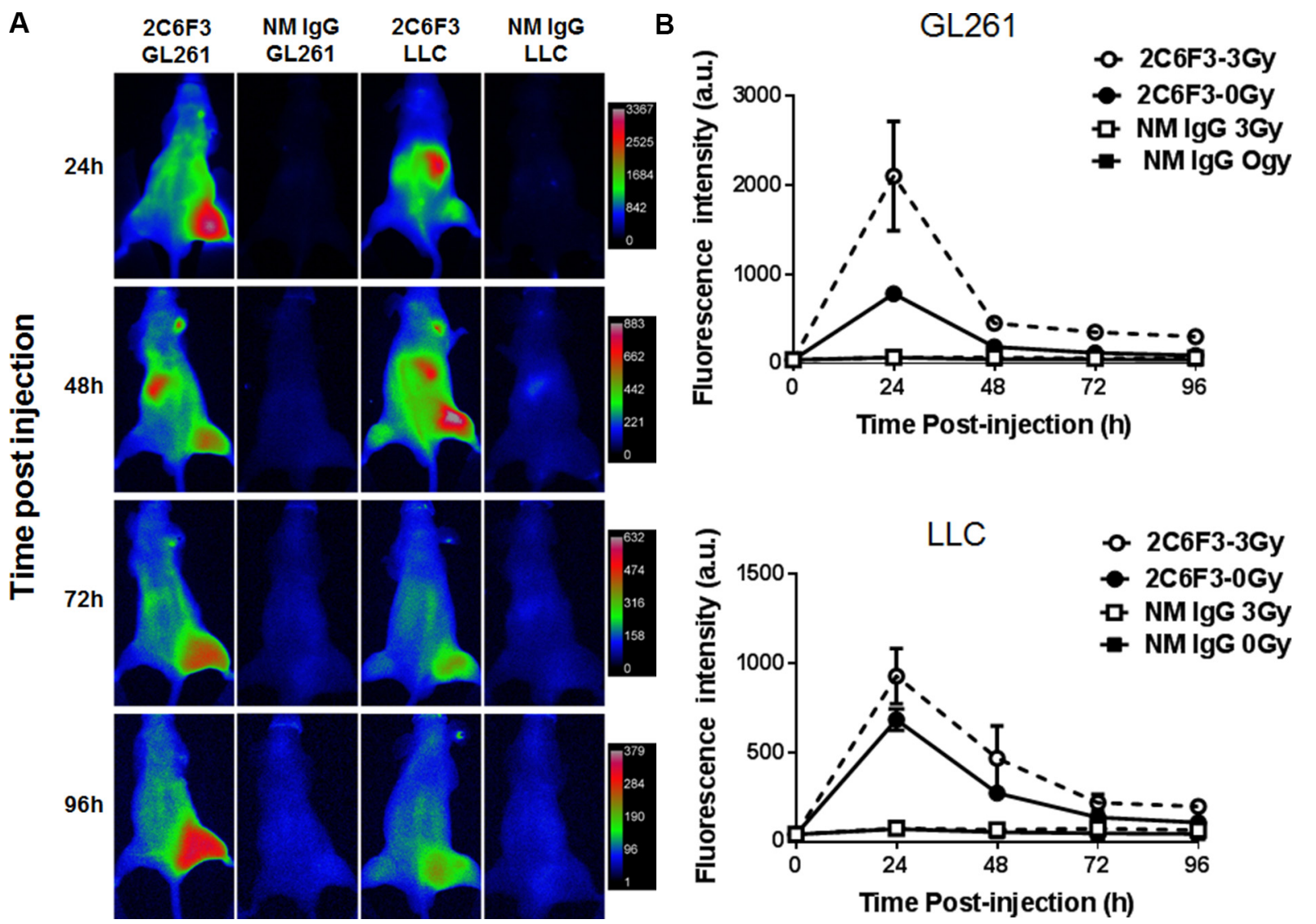

Figure 3: NIR imaging of mice bearing heterotopic tumors. (A) Mice bearing heterotopic LLC or GL261 tumors were treated with 3 fractions of 3 Gy over the course for 24 hours radiation or sham treated followed by intravenous administration of 50 $\mu \mathrm{g} 2 \mathrm{C} 6 \mathrm{~F} 3-$ AF750 or normal mouse IgG-AF750. (B) Line graph showing the mean fluorescence intensity of 2C6F3-AF750 or NM IgG-AF750 at various times post injection in irradiated and sham treated tumors. 


\section{Radioimmunotherapy with ${ }^{90}$ Y-DTPA-2C6F3 antibody}

Yttrium-90 $\left({ }^{90} \mathrm{Y}\right)$ is a therapeutic agent that is used routinely for cancer therapy. The therapeutic efficacy of ${ }^{90} \mathrm{Y}-\mathrm{DTPA}-2 \mathrm{C} 6 \mathrm{~F} 3$ was evaluated in athymic nude mice bearing heterotopic human A549 lung cancer tumors. A single dose of $250 \mu \mathrm{Ci}$ of ${ }^{90} \mathrm{Y}$-DTPA-2C6F3 was administered via intravenous tail vein injection in a cohort of six mice bearing hind limb tumors. The second cohort of 6 tumor-bearing mice treated with unlabeled DTPA-2C6F3 antibody was used as controls. Mice treated with $250 \mu \mathrm{Ci}$ of ${ }^{90} \mathrm{Y}-\mathrm{DTPA}-2 \mathrm{C} 6 \mathrm{~F} 3$ showed delayed tumor growth when compared to the cohort that received the unlabeled DTPA-2C6F3 (Figure 6A). There was a significant tumor growth delay on day 25 in mice treated with either $250 \mu \mathrm{Ci}$ of ${ }^{90} \mathrm{Y}-\mathrm{DTPA}-2 \mathrm{C} 6 \mathrm{~F} 3$ when compared to the control group that received the unlabeled DTPA-2C6F3 (Figure 6B).

\section{C6F3 antibody mediates ADCC and ADCP in vitro}

Many antibodies that are being used in the clinic for cancer therapy are known to elicit ADCC and ADCP mechanisms. Therefore, we evaluated the potential of $2 \mathrm{C} 6 \mathrm{~F} 3$ to mediate immune cell activation in vitro. Activation of mouse NK cell-mediated tumor cell lysis was performed by measuring LDH release from tumor cells treated with $2 \mathrm{C} 6 \mathrm{~F} 3$ antibody. $2 \mathrm{C} 6 \mathrm{~F} 3$ showed significantly higher killing of irradiated LLC cells (1.7 fold) when compared to irradiated LLC cells treated with NM-IgG (1.1 fold; Figure 7A).

We also evaluated antibody dependent dendritic cell-mediated phagocytosis of LLC. LLC cells treated with 2C6F3 showed enhanced phagocytosis (33\%) compared to LLC cells treated with NM-IgG (12\% Figure 7B).
A

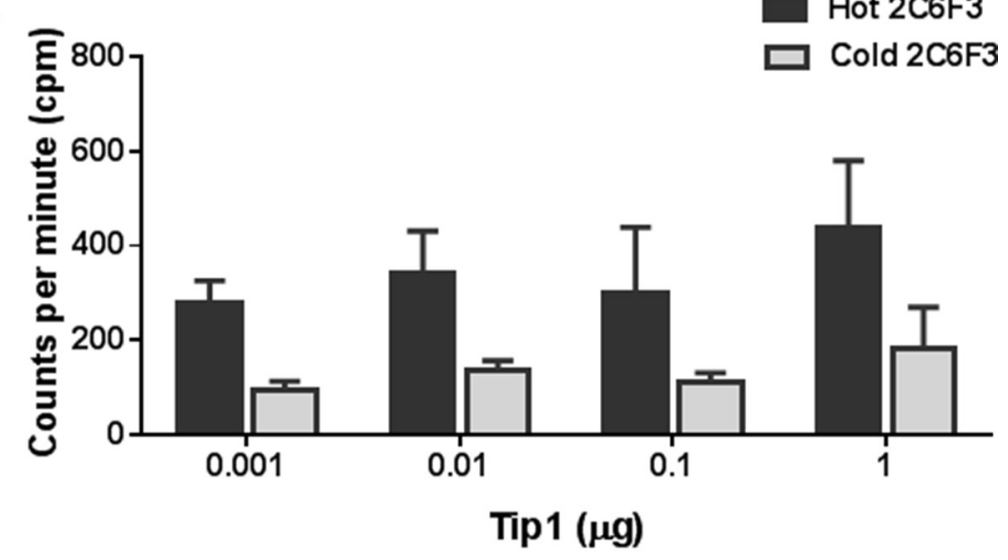

B

Sham

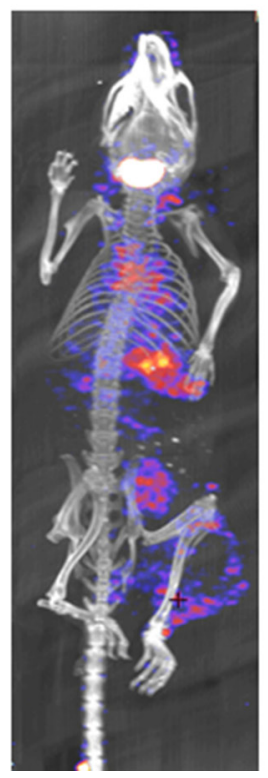

IR

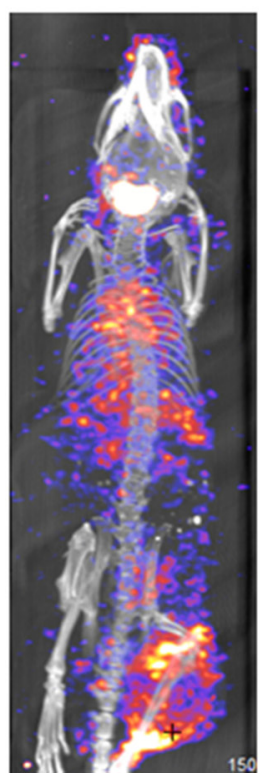

Figure 4: ${ }^{125}$ I labeling of $2 \mathrm{C6F} 3$ does not affect the efficacy of binding and SPECT imaging. (A) Bar graph showing ELISA analysis of the competition of unconjugated $2 \mathrm{C} 6 \mathrm{~F} 3$ with ${ }^{125} \mathrm{I}-2 \mathrm{C} 6 \mathrm{~F} 3$ to various concentrations of recombinant TIP-1 protein. (B) $\mathrm{CT} / \mathrm{SPECT}$ imaging of C57/BL6 mice's hind limb LLC tumors injected with ${ }^{125} \mathrm{I}-2 \mathrm{C} 6 \mathrm{~F} 3$. 


\section{DISCUSSION}

Recent success with immunotherapy against various cancers has generated a need for identifying and developing antibodies against specific cancer targets. In this study, we developed and evaluated 2C6F3, a monoclonal antibody that specifically binds to TIP-1 for radioimmunotherapy. TIP-1 is overexpressed in various cancers including lung cancer [14], breast cancer [9] and glioblastoma [10]. TIP-1 consists of a single PDZ domain and has been showed to have various biological functions. These include the stress response [15], cell proliferation [16], cell migration [10] and radioprotection [17]. The levels of TIP-1 expression in patients with glioblastoma has been reported to be a prognostic factor for disease progression [18] and correlated with shorter survival [10]. It has been reported that TIP-1 is induced on the cell surface after radiation in lung cancer and has been implicated as a molecular biomarker for tumor response to radiation [6]. Previously we have demonstrated improved radiation therapy with a peptide that specifically bound to TIP-1 (HVGGSSV) conjugated with nano-albumin-paclitaxel. HVGGSSV-nabpaclitaxel showed tumor-specific binding and enhanced bioavailability of the drug [11].

A

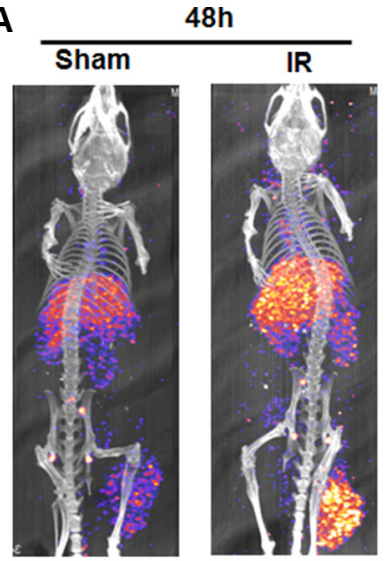

B

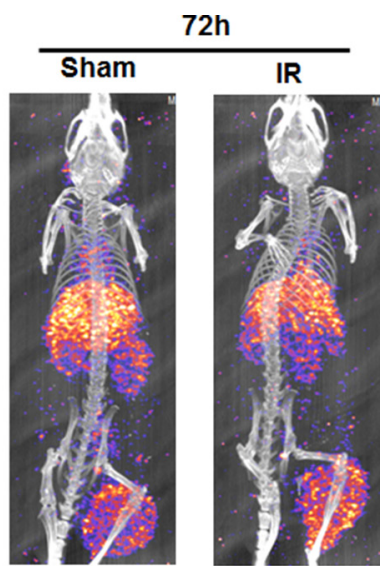
binding to irradiated GL261 and LLC tumors when compared to mice injected with normal mouse IgGAF750 alone at $24 \mathrm{~h}$ and $48 \mathrm{~h}$ (Figure 3A and 3B). This indicated that the monoclonal antibody against TIP-1 is able to specifically bind lung cancer tumors and glioblastoma. To develop a monoclonal antibody for therapy, monitoring its specificity and distribution is particularly important. The specificity and distribution of antibodies can be monitored noninvasively using PET or SPECT in preclinical mouse tumor models. We labeled 2C6F3 with ${ }^{111}$ In using DTPA as a chelator and imaged heterotopic LLC tumors using SPECT/CT. SPECT/ $\mathrm{CT}$ imaging at $48 \mathrm{~h}$ and $72 \mathrm{~h}$ revealed that ${ }^{111}$ In-labeled DTPA-2C6F3 bound to LLC tumors (Figure 5A). Lung
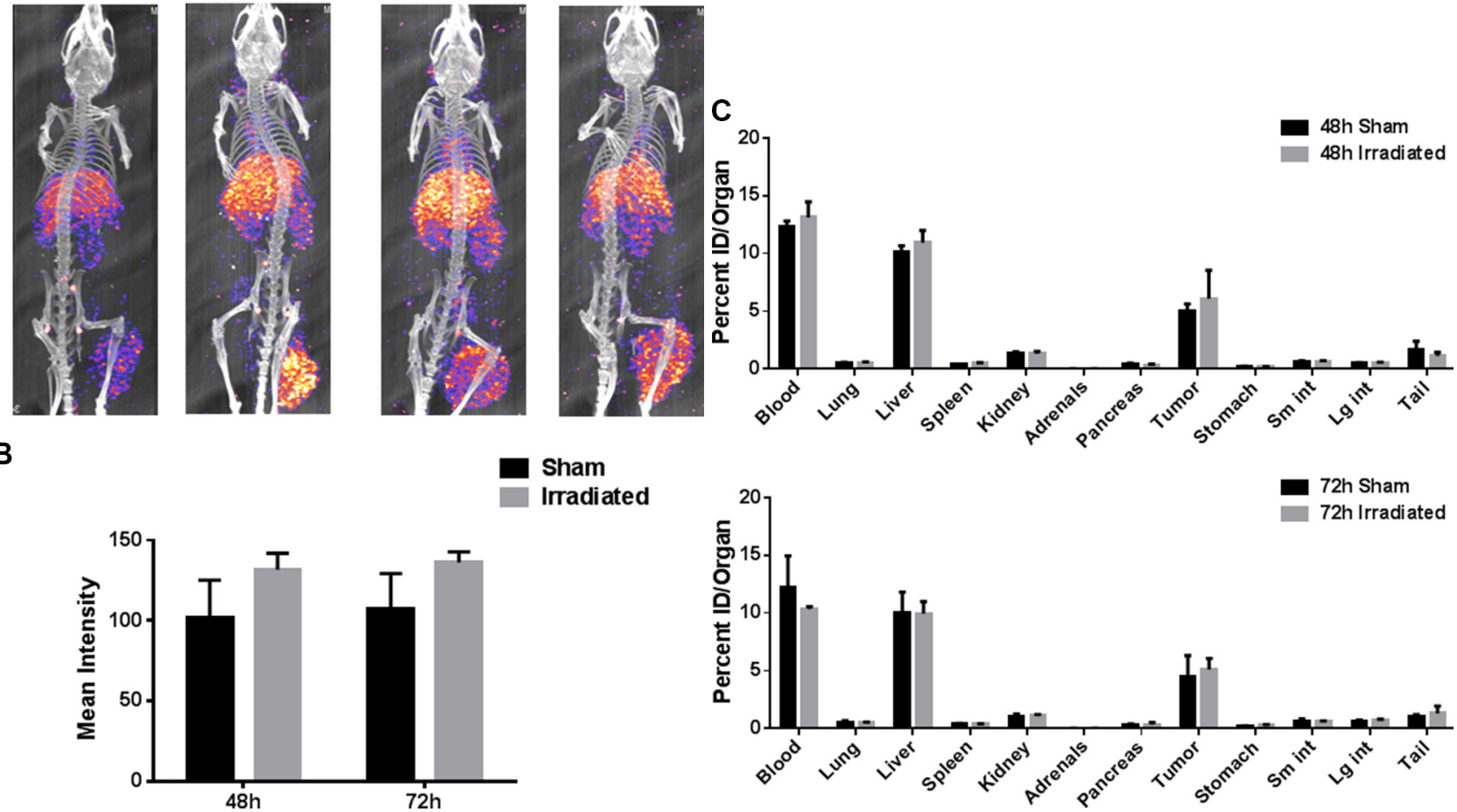

Figure 5: SPECT imaging of the heterotopic LLC lung tumor model with ${ }^{111}$ In labeled 2C6F3. (A) SPECT-CT images of mice bearing heterotopic LLC tumors injected with $250 \mu \mathrm{Ci}{ }^{111} \mathrm{In}-2 \mathrm{C} 6 \mathrm{~F} 3$. Enhanced tumor binding of the radiolabeled $2 \mathrm{C} 6 \mathrm{~F} 3 \mathrm{was}$ observed at $48 \mathrm{~h}$ and $72 \mathrm{~h}$ post-irradiation $(3 \mathrm{~Gy} \times 3)$. (B) The mean intensity of the irradiated and sham-irradiated tumors calculated from drawing ROI from SPECT imaging using ImageJ (C) Biodistribution of ${ }^{111}$ In labeled 2C6F3 in the irradiated and sham treated heterotopic LLC tumor model. Mice injected with $20 \mu \mathrm{Ci}{ }^{111} \mathrm{In}-2 \mathrm{C} 6 \mathrm{~F} 3$ and organs were harvested $48 \mathrm{~h}$ and $72 \mathrm{~h}$ post-injection. Shown are the biodistribution of ${ }^{111}$ In labeled $2 \mathrm{C} 6 \mathrm{~F} 3$ in various organs. 
cancer expresses TIP1, and irradiation can enhance the expression of TIP-1. The enhanced expression of TIP-1 is dependent upon various factors including cell type, irradiation dose, and time post-irradiation. Although not statistically significant, we observed enhanced binding in irradiated tumors compared to sham-irradiated control tumors. Optimizing the expression of TIP1after irradiation and addition of cohorts of mice could show significant differences between irradiated and sham-irradiated tumors. The biodistribution data supported the SPECT imaging data. Higher uptake of ${ }^{111} \mathrm{In}$ - DTPA-2C6F3 was observed in LLC tumors (Figure 5B and 5C). ${ }^{111} \mathrm{In}-\mathrm{DTPA}-2 \mathrm{C6F} 3$ was also observed in the blood and liver. It has been reported that clearance of radiolabeled antibodies from the blood is dose dependent and is also elevated in patients with high tumor burden [19]. Thus, the higher blood and liver levels could be due to the circulation of ${ }^{111} \mathrm{In}$ - DTPA$2 \mathrm{C} 6 \mathrm{~F} 3$ and tumor burden. Liver uptake of therapeutic antibodies conjugated with drugs including radioisotopes has been reported [20-22]. The enhanced accumulation of $2 \mathrm{C} 6 \mathrm{~F} 3$ antibody in the liver could be due to its clearance from the liver. This would need to be optimized before translating 2C6F3 into the clinic. It has been suggested that alterations in chelation and linker chemistry may reduce liver uptake of antibodies [23]. Another approach could involve pre-targeting with a streptavidin-conjugated $2 \mathrm{C} 6 \mathrm{~F} 3$ followed by ${ }^{111}$ In-labeled biotin. This pre-targeting approach is under investigation for several different radio-immunoconjugates used for imaging and therapy [24-27]. Antibodies by themselves may have limited

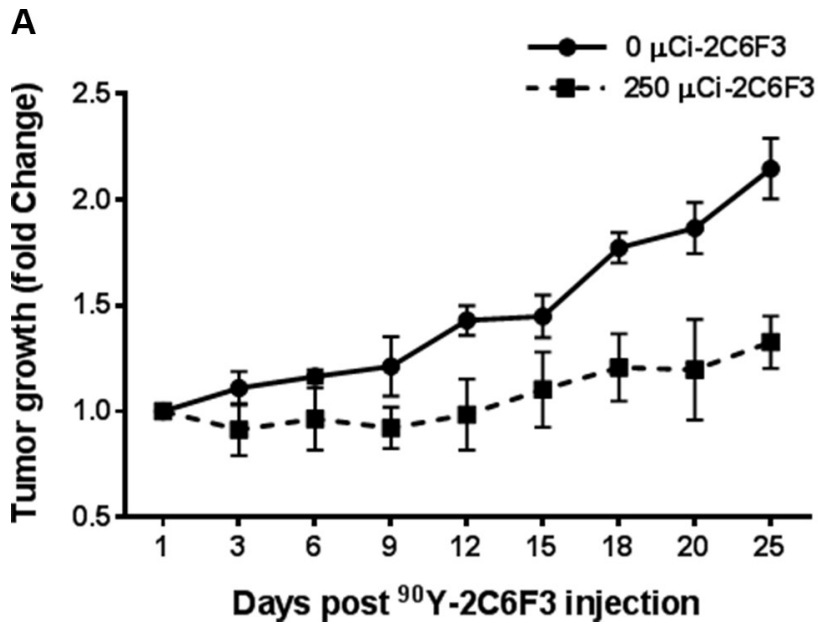

B

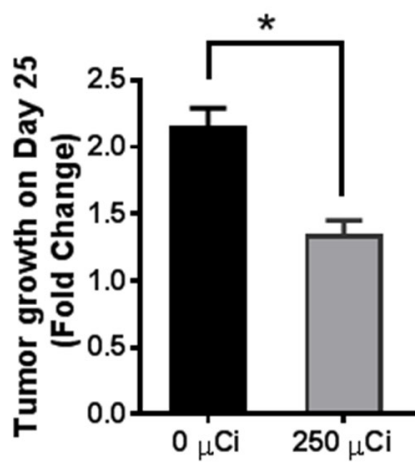

Figure 6: Radioimmunotherapy of heterotopic human lung cancer tumors with yttrium-90 $\left({ }^{90} \mathrm{Y}\right) 2 \mathrm{C6F3}$ antibody. (A) Athymic nude mice bearing subcutaneous A549 human lung tumors were given a single intravenous injection of $250 \mu \mathrm{Ci}$ of ${ }^{90} \mathrm{Y}-\mathrm{DTPA}$ $2 \mathrm{C} 6 \mathrm{~F} 3$ or unlabeled DTPA-2C6F3. Shown are the mean tumors volumes of treatment groups as fold change over time. (B) Tumor growth on the 25 th day after treatment $(*$ indicates a $P$ value $<0.05)$.

A

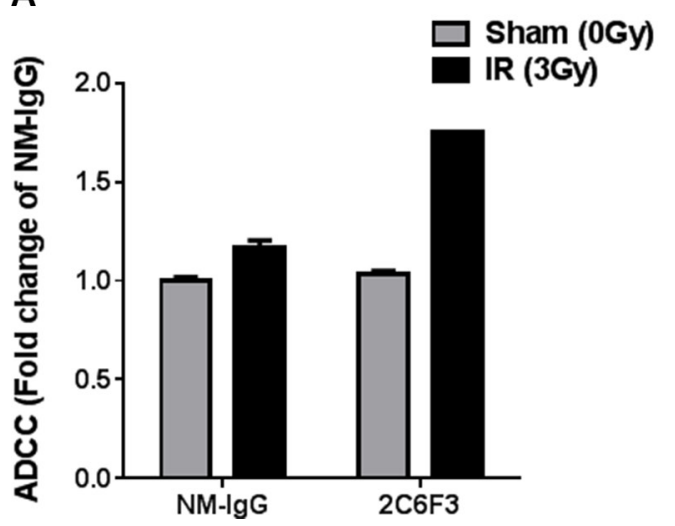

B

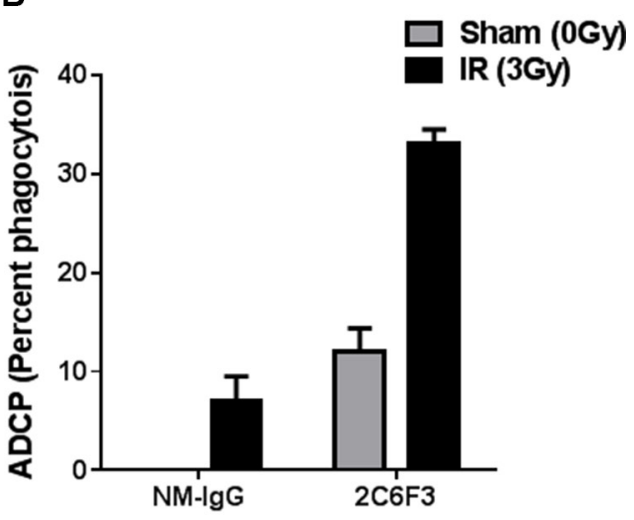

Figure 7: 2C6F3 antibody activates ADCC and ADCP in vitro. (A) Antibody-mediated activation of murine NK cells in vitro leading to LDH release from LLC cells with or without irradiation. Bar graphs show means with SD of LDH release from triplicates. Data has been normalized after subtracting the values from media alone, tumor cells alone and NK cells alone. (B) Antibody-mediated phagocytosis by dendritic cells in vitro. Bar graphs show percent phagocytosis by DC from triplicates. 
therapeutic efficacy. Therefore, more emphasis is being placed on using antibodies for delivery of toxic agents such as radioisotopes. ${ }^{90}$ Y-conjugated antibodies have been effectively utilized for cancer therapy. For example, Cetuximab that targets the epidermal growth factor conjugated with ${ }^{90} \mathrm{Y}$ was effective in controlling tumor growth [28]. In the present study, we targeted TIP-1 using 2C6F3 labeled with ${ }^{90} \mathrm{Y}$ to treat human heterotopic lung cancer. $2 \mathrm{C} 6 \mathrm{~F} 3$ labeled with ${ }^{90} \mathrm{Y}$ will irradiate the tumors, and this irradiation is sufficient to enhance expression of TIP-1. Treatment of a human heterotopic lung cancer with ${ }^{90} \mathrm{Y}$ - DTPA-2C6F3 led to a significant tumor growth delay (Figure 6).

Antibodies mediate tumor cell killing by several mechanisms which can be broadly classified as direct (receptor blockade, induction of apoptosis, delivery of cytotoxic agents) or indirect (immune-mediated cell killing). Antibodies can engage the immune system and mediate complement-dependent cytotoxicity (CDC), antibody-dependent cellular cytotoxicity (ADCC), antibodydependent cellular phagocytosis (ADCP) along with regulating $\mathrm{T}$ cell function $[29,30]$. We observed that $2 \mathrm{C} 6 \mathrm{~F} 3$ has the ability to mediate both ADCC by mouse NK cells and ADCP by mouse dendritic cells (Figure 7). A similar mechanism of action has been observed for antibodies approved by FDA for cancer treatment, e.g. Trastuzumab (targets ERBB2), Cetuximab (targets EGFR), Rituximab (targets CD20) and Bexxar (targets CD20) [29, 30]. This ability of 2C6F3 to mediate ADCC and ADCP would most likely enhance the therapeutic efficacy of this antibody. However, further evaluation in a mouse tumor model is needed to confirm this potential for indirect effects in vivo.

In conclusion, we have demonstrated that TIP-1 is a suitable target for immunotherapy and imaging of cancer; the monoclonal antibody against TIP-1, 2C6F3, can be used to specifically image and treat tumors as a radio-immunoconjugate moiety. Moreover, since TIP-1 is induced by radiation $[6,11]$ it is an attractive antibody to use in conjunction with radiation therapy.

\section{MATERIALS AND METHODS}

\section{Cell lines}

Human lung adenocarcinoma A549, mouse lung cancer LLC, mouse glioblastoma GL-261 and human glioblastoma D54 cells were cultured in DMEM/F12, human lung cancer H460 cells in RPMI 1640 with 10\% fetal bovine serum, penicillin, and streptomycin. They were maintained at $37^{\circ} \mathrm{C}$ in a $5 \% \mathrm{CO}_{2}$ incubator.

\section{Mouse tumor models and irradiation}

All animal studies were performed in accordance with the guidelines of the IACUC. Washington University Division of Comparative Medicine approved the animal protocol. Heterotopic tumor models were established in
6 to 8-week-old female athymic nude or C57BL/6 mice (Envigo, USA). Mice were injected subcutaneously in the hind limb with GL-261 $\left(1 \times 10^{6}\right.$ cells $)$, A549 $\left(1 \times 10^{6}\right.$ cells $)$ or LLC $\left(5 \times 10^{5}\right.$ cells $)$. Once the tumors were palpable, mice were stratified into treatment groups having similar tumor sizes. Tumors were sham irradiated or irradiated with 3 fractions of 3 Gy ( $\operatorname{Rad}$ Source RS2000) over a period of 24 hours after anesthetizing the mice using 1-3\% isoflurane and shielding the rest of the body with lead.

\section{Anti-TIP-1 mouse monoclonal antibody production and purification}

Six-week-old female BALB/C mice (Envigo, USA) were immunized with recombinant human TIP-1 protein $(50 \mu \mathrm{g})$ mixed with equal volume of adjuvant (TiterMax Gold adjuvant, Sigma). One month after initial immunization, the mice were boosted with TIP-1 without adjuvant. Three boosters were given at two-week intervals. The mouse having the high immune response to the TIP-1 antigen was chosen as the B cell donor for cell fusion. Spleen cells were fused with mouse myeloma cells $\left(2 \times 10^{7}\right.$ per spleen). The fused cells were plated into 96 well tissue culture plates with HAT selection medium. Fifteen days post fusion hybridoma culture supernatants were assayed. Hybridomas that produced antibodies were sub-cloned to get single-cell clones.

Positive hybridoma clones (e.g. clone 2C6F3) were expanded in serum-free medium. The monoclonal antibodies produced in the serum-free medium were purified by using protein $\mathrm{A} / \mathrm{G}$ columns.

\section{Anti-TIP-1 monoclonal antibody 2C6F3 epitope mapping}

Twenty peptides that were 10 amino acids long with 4 amino acid overlaps encompassing the 124 amino acids of the human TIP-1 protein were used for epitope mapping. The 96 well ELISA plates were coated with the 20 peptides along with the positive and negative controls. The plates were washed with PBS containing $0.1 \%$ Tween 20 and blocked with $3 \%$ BSA for 45 minutes. The plates were washed and incubated with $5 \mu \mathrm{g} / \mathrm{ml}$ TIP-1 monoclonal antibody $2 \mathrm{C} 6 \mathrm{~F} 3$ at RT for 2 hours. The plates were washed and incubated with secondary anti-mouse IgG horseradish peroxidase conjugated antibody at RT for 2 hours. After washing, the plates were developed with ABTS substrate and read at $405 \mathrm{~nm}$ using an ELISA reader (BioTek Instruments).

\section{Modeling the 2C6F3 epitope on TIP-1}

To identify the location of the epitope on the threedimensional (3D) structure of TIP-1, a published crystal structure, 3DIW was used [13]. PyMOL software was used to highlight the epitope of $2 \mathrm{C} 6 \mathrm{~F} 3$ in the TIP-1 3D structure. 


\section{Monitoring TIP-1 surface expression by flow cytometry}

The expression of TIP- 1 in on the surface lung cancer (LLC, A549, and H460) and Glioma (D54, GL261) cell lines was evaluated using a flow cytometer. Cancer cells were irradiated $(3 \mathrm{~Gy} \times 3)$ and harvested $24 \mathrm{~h}$ and $48 \mathrm{~h}$ postirradiation. Cells were incubated with $2 \mathrm{C} 6 \mathrm{~F} 3(30 \mu \mathrm{g} / \mathrm{ml})$ for $1 \mathrm{~h}$ on ice followed by incubation for $1 \mathrm{~h}$ with antimouse Alexa488 labeled secondary antibody. Propidium iodide was added to the cells prior to acquisition for flow cytometric analysis for the exclusion of dead cells. Cells were analyzed using a MACSQuant Analyzer flow cytometer (Miltenyi Biotec) and the data were analyzed with FlowJo software (Tree Star Inc.).

\section{Optical imaging}

The TIP-1 mAb 2C6F3 or the normal mouse IgG (NM-IgG) was labeled with Alexa Fluor 750 as per manufacturer's instructions (Thermo Fisher). Tumors were induced by injecting LLC $\left(0.5 \times 10^{6}\right)$ or GL261 $\left(1 \times 10^{6}\right)$ cells in both the hind limbs of nude mice. The right hind limb tumors were irradiated with 3 fractions of 3 Gy over a course of $24 \mathrm{~h}$ while the tumors on the left hind limb were used as the sham-irradiated controls. The tumorbearing mice were then injected with $50 \mu \mathrm{g}$ of Alexa Flour-750 labeled 2C6F3 (2C6F3-AF750) or normal mouse IgG (IgG-AF750) via the tail vein. For optical imaging, the mice were anesthetized with $2 \%$ isoflurane and imaged using the In-Vivo Multispectral Imaging System (Bruker Biospin). Fluorescence was detected using $730 \mathrm{~nm}$ excitation and $790 \mathrm{~nm}$ emission filters with $60 \mathrm{~s}$ acquisition time, F-stop 2.4, and $2 \times 2$ binning. ROI analysis was performed using NIH ImageJ image processing software and mean fluorescence intensity values reported as arbitrary units (a.u.).

\section{${ }^{125}$ I labeling and binding assay}

2C6F3 $(1.0 \mathrm{mg})$ was mixed with ${ }^{125} \mathrm{I}(5.0 \mathrm{mCi})$ in an Iodogen-coated glass tube. The mixture was incubated at room temperature for $15 \mathrm{~min}$ and then purified by passing through a PD-10 size-exclusion column. The purity of the ${ }^{125}$ I labeled 2C6F3 was determined using radio-thin layer chromatography (radio-TLC). For binding assays, the TLC plate was coated with $0.001,0.01,0.1$ and $1 \mu \mathrm{g}$ of recombinant TIP- 1 followed by the addition of $0.1 \mu \mathrm{g}$ of ${ }^{125} \mathrm{I}$ labeled $2 \mathrm{C} 6 \mathrm{~F} 3(0.3 \mu \mathrm{Ci} / \mu \mathrm{g})$ and incubated for $1 \mathrm{~h}$ at room temperature. For blocking assays, the plate was coated with $0.001,0.01,0.1$ and $1 \mu \mathrm{g}$ of recombinant TIP- 1 and $20 \mu \mathrm{g}$ of cold $2 \mathrm{C} 6 \mathrm{~F} 3$ antibody were added per well and incubated for $1 \mathrm{~h}$ at room temperature. To this $0.1 \mu \mathrm{g}$ of ${ }^{125} \mathrm{I}$ labeled $2 \mathrm{C} 6 \mathrm{~F} 3(0.3 \mu \mathrm{Ci} / \mu \mathrm{g})$ was added per well and incubated for $1 \mathrm{~h}$ at room temperature. The binding efficiency was measured by monitoring the ${ }^{125} \mathrm{I}$ activity using a scintillation counter.

\section{Conjugation of DTPA to 2C6F3 antibody}

Diethylene triamine penta acetic acid (DTPA)-NCS was added to 2C6F3 in DTPA to antibody ratio of 10:1 in $0.1 \mathrm{MNa}_{2} \mathrm{CO}_{3}(\mathrm{pH} \sim 9)$ buffer. The reaction mixture was incubated at $37^{\circ} \mathrm{C}$ for $1 \mathrm{~h}$ with continuous mixing. The unconjugated DTPA was removed from the conjugated antibody using a $40 \mathrm{kDa}$ Zeba Spin desalting column (Thermo Fisher). The DTPA-conjugated antibody was stored at $4^{\circ} \mathrm{C}$ in PBS.

\section{Radiolabeling of DTPA-conjugated 2C6F3}

${ }^{111} \mathrm{InCl}_{3}$ (370MBq $\mathrm{ml}^{-1}$ in $0.5 \mathrm{M} \mathrm{Hcl}, \mathrm{pH} 1.5$ ) was obtained from Mallinckrodt Pharmaceuticals. An equal volume of ammonium acetate $(0.1 \mathrm{M} ; \mathrm{pH} 8.1)$ was added to ${ }^{111} \mathrm{InCl}_{3}(\mathrm{pH} 1.5)$ to attain a $\mathrm{pH}$ of 5.5. DTPA-2C6F3 was added at specific activity of $1 \mathrm{mCi}^{111} \mathrm{InCl}_{3}$ per $\mathrm{mg}$ of antibody. The mixture was incubated at $37^{\circ} \mathrm{C}$ for $1 \mathrm{~h}$ on thermomixer. Labeling efficiency was determined using instant thin-layer chromatography (ITLC) using $50 \mathrm{mM}$ DTPA. If the detected labeling efficiency was less than $95 \%$, then the mixture was further purified with spin desalting column (40 kDa) to yield more than $95 \%$ purity. The ${ }^{111}$ In labeled DTPA-2C6F3 was used for SPECT imaging and biodistribution study.

\section{Small animal SPECT/CT imaging}

Mice bearing heterotopic tumors were injected intravenously either with ${ }^{125} \mathrm{I}$ labeled $2 \mathrm{C} 6 \mathrm{~F} 3$ or ${ }^{111} \mathrm{In}$ DTPA-2C6F3. Whole body SPECT images were obtained at 48 and $72 \mathrm{~h}$ post injection (p.i.) using a SPECT/CT imager (Bioscan Inc., Washington, DC, USA) fitted with $2 \mathrm{~mm}$ pinhole collimators in the helical scanning mode. Mice were placed in prone position and scanned under anesthesia $(0.5 \mathrm{~L} / \mathrm{min} 1.5 \%$ isoflurane in air). A $45-\mathrm{keV}$ helical CT scan was performed first and then the SPECT acquisition was performed at 24 projections with $60 \mathrm{~s}$ per projection. Tomographic data were reconstructed iteratively with InVivoScope and HiSPECT software for $\mathrm{CT}$ and SPECT, respectively. The binding intensity of $2 \mathrm{C} 6 \mathrm{~F} 3$ in irradiated and sham-irradiated tumors was evaluated using ImageJ software by drawing the regions of interest (ROI) and depicted as mean intensity.

\section{Biodistribution studies}

Mice ( $n=3$ per group) bearing heterotopic LLC tumors were injected intravenously with $20 \mu \mathrm{Ci}{ }^{111} \mathrm{In}$ DTPA-2C6F3. The labeled 2C6F3 in blood, lung liver, spleen, kidney, adrenals, pancreas, stomach, small and large intestine, tumor and tail was determined. The mice were sacrificed and the organs of interest were dissected/ collected, weighed, and counted in a gamma counter along with a standard of the injected activity to allow calculation of the injected dose per organ (\% ID/organ). 


\section{Tumor growth delay with yttrium-90 $\left({ }^{90} \mathrm{Y}\right)$ - DTPA-2C6F3 antibody}

The growth delay of heterotopic A549 (human lung cancer) tumors with ${ }^{90} \mathrm{Y}$-DTPA-2C6F3 was evaluated in athymic nude mice. Cohorts of six A549 tumor-bearing mice (average tumor size $450 \pm 50 \mathrm{~mm}^{3}$ and average mouse weight $31.24 \pm 1.23 \mathrm{~g}$ ) were treated with a single intravenous injection of $250 \mu \mathrm{Ci}$ of ${ }^{90} \mathrm{Y}$ - DTPA-2C6F3. A cohort of 6 mice treated with $200 \mu \mathrm{g}$ of unlabeled DTPA$2 \mathrm{C} 6 \mathrm{~F} 3$ was used as controls. Tumor measurements and animal weights were recorded every 2-3 days and tumor volumes were calculated as fold change from the size of the tumor at the beginning of the therapy.

\section{Antibody dependent cell-mediated cytotoxicity (ADCC)}

Murine natural killer cells (NK cells) were isolated from spleen by using a MagCellect mouse NK cell Isolation Kit (R\&D Systems, Inc.) as per manufacturer's protocol. LLC cells were cultured in 96 well plate (5000 cells/well). Following incubation for 40 hours, the cells were irradiated with 3 Gy or sham ( $0 \mathrm{~Gy}$ ) and allowed to incubate for another 4 hours. Tumor cells were then treated with $10 \mu \mathrm{g} / \mathrm{ml}$ of mouse anti TIP1 (2C6F3) or normal mouse $\operatorname{IgG}(\mathrm{NM}-\mathrm{IgG})$ antibody and incubated for additional 2 hours. The murine NK cells were added to the target tumor cells at a ratio of 5:1 (effector cells: target cells) and allowed to incubate for $16 \mathrm{~h}$. Following incubation, the culture supernatants were collected and analyzed for Lactate dehydrogenase (LDH) using an LDH cytotoxicity detection kit (Roche). The amount of LDH released was monitored as absorbance at $490 \mathrm{nM}$.

\section{Antibody dependent cell-mediated phagocytosis (ADCP)}

LLC cells were irradiated ( 3 Gy), stained with DiI dye (Thermo Scientific) and then treated with 2C6F3 antibody. Mouse dendritic cells (DC) were isolated and grown in culture media containing rmGM-CSF, rmTNF $\alpha$ and rmCD40 ligand for maturation. These mature DC were then co-cultured with LLC cells pretreated with 2C6F3 (target) at a ratio of 1:1 for $24 \mathrm{hrs}$. The co-cultured cells were then fixed and counterstained with DAPI. The number of phagocytized tumor cells was quantified by counting the number of DC that engulfed DiI-labeled cancer cells in 50 high power fields using fluorescent microscope (Olympus).

\section{Statistical analyses}

The mean and standard error of the mean (SEM) of each treatment group were calculated based on at least three replicates for all experiments. Experiments were repeated at least three times. All pairwise comparisons, including calculation of $P$ values, were done using the Student's $t$-test. The significance of the difference in tumor growth rates in the treatment and control groups was determined using Wilcoxon one-sided tests.

\section{ACKNOWLEDGMENTS}

We acknowledge the Siteman Cancer Center Small Animal Imaging Core and we thank Nicole Fettig, Amanda Klaas for their technical assistance. We thank Dr. Andrei Laszlo for reviewing this manuscript.

\section{CONFLICTS OF INTEREST}

Dennis Hallahan licensed 2C6F3 antibody to Medical Guidance Systems for the development of the humanized antibody for planned clinical trials.

\section{FUNDING}

National Cancer Institute grants R01-174966, R21170169, R41-192413 AACR/Breast Cancer Research Foundation, BJH Foundation, Siteman Cancer Center P30 and Lung Cancer Research Foundation.

\section{REFERENCES}

1. Hogarth PM, Pietersz GA. Fc receptor-targeted therapies for the treatment of inflammation, cancer and beyond. Nat Rev Drug Discov. 2012; 11:311-331.

2. Keizer RJ, Huitema AD, Schellens JH, Beijnen JH. Clinical pharmacokinetics of therapeutic monoclonal antibodies. Clin Pharmacokinet. 2010; 49:493-507.

3. Teicher BA, Chari RV. Antibody conjugate therapeutics: challenges and potential. Clin Cancer Res. 2011; 17: 6389-6397.

4. Reichert JM. Antibodies to watch in 2013: Mid-year update. MAbs. 2013; 5:513-517.

5. Lamberts LE, Williams SP, Terwisscha van Scheltinga AG, Lub-de Hooge MN, Schroder CP, Gietema JA, Brouwers AH, de Vries EG. Antibody positron emission tomography imaging in anticancer drug development. J Clin Oncol. 2015; 33:1491-1504.

6. Wang H, Yan H, Fu A, Han M, Hallahan D, Han Z. TIP-1 translocation onto the cell plasma membrane is a molecular biomarker of tumor response to ionizing radiation. PLoS One. 2010; 5:e12051.

7. Rousset R, Fabre S, Desbois C, Bantignies F, Jalinot P. The C-terminus of the HTLV-1 Tax oncoprotein mediates interaction with the PDZ domain of cellular proteins. Oncogene. 1998; 16:643-654.

8. Besser J, Leito JT, van der Meer DL, Bagowski CP. Tip-1 induces filopodia growth and is important for gastrulation 
movements during zebrafish development. Dev Growth Differ. 2007; 49:205-214.

9. Han M, Wang H, Zhang HT, Han Z. The PDZ protein TIP-1 facilitates cell migration and pulmonary metastasis of human invasive breast cancer cells in athymic mice. Biochem Biophys Res Commun. 2012; 422:139-145.

10. Wang $\mathrm{H}$, Han $\mathrm{M}$, Whetsell W Jr., Wang J, Rich J, Hallahan D, Han Z. Tax-interacting protein 1 coordinates the spatiotemporal activation of Rho GTPases and regulates the infiltrative growth of human glioblastoma. Oncogene. 2014; 33:1558-1569.

11. Hariri G, Yan H, Wang H, Han Z, Hallahan DE. Radiationguided drug delivery to mouse models of lung cancer. Clin Cancer Res. 2010; 16:4968-4977.

12. Lowery A, Onishko H, Hallahan DE, Han Z. Tumortargeted delivery of liposome-encapsulated doxorubicin by use of a peptide that selectively binds to irradiated tumors. J Control Release. 2011; 150:117-124.

13. Zhang J, Yan X, Shi C, Yang X, Guo Y, Tian C, Long J, Shen Y. Structural basis of beta-catenin recognition by Taxinteracting protein-1. J Mol Biol. 2008; 384:255-263.

14. Ferraro DJ, Bhave SR, Kotipatruni RP, Hunn JC, Wildman SA, Hong C, Dadey DY, Muhoro LK, Jaboin JJ, Thotala D, Hallahan DE. High-throughput identification of putative receptors for cancer-binding peptides using biopanning and microarray analysis. Integr Biol (Camb). 2013; 5:342-350.

15. Reynaud C, Fabre S, Jalinot P. The PDZ protein TIP-1 interacts with the Rho effector rhotekin and is involved in Rho signaling to the serum response element. J Biol Chem. 2000; 275:33962-33968.

16. Kanamori M, Sandy P, Marzinotto S, Benetti R, Kai C, Hayashizaki Y, Schneider C, Suzuki H. The PDZ protein tax-interacting protein-1 inhibits beta-catenin transcriptional activity and growth of colorectal cancer cells. J Biol Chem. 2003; 278:38758-38764.

17. Han M, Wang H, Zhang HT, Han Z. Expression of TIP-1 confers radioresistance of malignant glioma cells. PLoS One. 2012; 7:e45402.

18. Phillips HS, Kharbanda S, Chen R, Forrest WF, Soriano RH, Wu TD, Misra A, Nigro JM, Colman H, Soroceanu L, Williams PM, Modrusan Z, Feuerstein BG, et al. Molecular subclasses of high-grade glioma predict prognosis, delineate a pattern of disease progression, and resemble stages in neurogenesis. Cancer Cell. 2006; 9:157-173.

19. Bruno R, Washington CB, Lu JF, Lieberman G, Banken L, Klein P. Population pharmacokinetics of trastuzumab in patients with HER2+ metastatic breast cancer. Cancer Chemother Pharmacol. 2005; 56:361-369.
20. Sampath L, Kwon S, Ke S, Wang W, Schiff R, Mawad ME, Sevick-Muraca EM. Dual-labeled trastuzumab-based imaging agent for the detection of human epidermal growth factor receptor 2 overexpression in breast cancer. J Nucl Med. 2007; 48:1501-1510.

21. D’Huyvetter M, Vincke C, Xavier C, Aerts A, Impens N, Baatout S, De Raeve H, Muyldermans S, Caveliers V, Devoogdt N, Lahoutte T. Targeted radionuclide therapy with A 177Lu-labeled anti-HER2 nanobody. Theranostics. 2014; 4:708-720.

22. Tempero M, Leichner P, Baranowska-Kortylewicz J, Harrison K, Augustine S, Schlom J, Anderson J, Wisecarver J, Colcher D. High-dose therapy with 90Yttrium-labeled monoclonal antibody CC49: a phase I trial. Clin Cancer Res. 2000; 6:3095-3102.

23. Paik CH, Yokoyama K, Reynolds JC, Quadri SM, Min CY, Shin SY, Maloney PJ, Larson SM, Reba RC. Reduction of background activities by introduction of a diester linkage between antibody and a chelate in radioimmunodetection of tumor. J Nucl Med. 1989; 30:1693-1701.

24. Frampas E, Rousseau C, Bodet-Milin C, Barbet J, Chatal JF, Kraeber-Bodere F. Improvement of radioimmunotherapy using pretargeting. Front Oncol. 2013; 3:159.

25. Evans-Axelsson S, Timmermand OV, Bjartell A, Strand SE, Elgqvist J. Radioimmunotherapy for Prostate CancerCurrent Status and Future Possibilities. Semin Nucl Med. 2016; 46:165-179.

26. Bodet-Milin C, Kraeber-Bodere F, Eugene T, Guerard F, Gaschet J, Bailly C, Mougin M, Bourgeois M, FaivreChauvet A, Cherel M, Chevallier P. Radioimmunotherapy for Treatment of Acute Leukemia. Semin Nucl Med. 2016; 46:135-146.

27. Kraeber-Bodere F, Rousseau C, Bodet-Milin C, Frampas E, Faivre-Chauvet A, Rauscher A, Sharkey RM, Goldenberg DM, Chatal JF, Barbet J. A pretargeting system for tumor PET imaging and radioimmunotherapy. Front Pharmacol. 2015; 6:54.

28. Koi L, Bergmann R, Bruchner K, Pietzsch J, Pietzsch HJ, Krause M, Steinbach J, Zips D, Baumann M. Radiolabeled anti-EGFR-antibody improves local tumor control after external beam radiotherapy and offers theragnostic potential. Radiother Oncol. 2014; 110:362-369.

29. Scott AM, Wolchok JD, Old LJ. Antibody therapy of cancer. Nat Rev Cancer. 2012; 12:278-287.

30. Scott AM, Allison JP, Wolchok JD. Monoclonal antibodies in cancer therapy. Cancer Immun. 2012; 12:14. 